Available online on 15.04.2020 at http://jddtonline.info
Open Access to Pharmaceutical and Medical Research
unrestricted non-commercial use, provided the original work is properly cited

Open@Access

Review Article

\title{
Nasal In Situ Gel: Novel Approach for Nasal Drug Delivery
}

\author{
Sabale Anjalia, Kulkarni Abhijeet*b, Sabale Ajayc \\ a Department of Pharmaceutical Quality Assurance (PG), Sanjivani College of Pharmaceutical Education and Research, Kopar gaon, Maharashtra- \\ 423601, India \\ b Department of Pharmaceutical Quality Assurance, Sanjivani College of Pharmaceutical Education and Research, Kopargaon, Maharashtra- \\ 423601, India
}

c Sanjivani College of Pharmaceutical Education and Research, Kopargaon, Maharashtra-423601, India

\begin{abstract}
Nasal delivery is an alternative to oral or parenteral administration due to certain limitations such as absorption of the drug, drug targeting to particular organs can cause a problem for administration through oral route. The nasal route has also been successfully used for bypassing the blood-brain barrier and afterword delivering drug molecules to the central nervous system. Also, lag time related to oral drug delivery is reduces by this route and offers noninvasiveness, self-medication, patient comfort, and patient compliance. Extend drug delivery can be attained by different new dosage forms like in situ gel. In situ formulations are drug delivery systems. The in-situ gelling system is a process in which the solution forms of a gel before administration in the body, but once administrated, it undergoes gelation in-situ, to form a gel. In situ gelling system becomes very popular nowadays because of their several advantages over conventional drug delivery systems like a sustained and prolonged release of a drug, reduced Frequency of administration, improved patient compliance and comfort. Approaches towards the various formulation of in-situ gel concerning temperature, $\mathrm{pH}$, and physicochemical conditions. The in situ gel-forming polymeric formulations offer several advantages like sustained and prolonged action reduced Frequency of administration, in comparison to conventional drug delivery systems. From a manufacturing point of view, the production of such systems is less complex and thus lowers the investment and manufacturing cost. Various evaluation parameters are considered during the preparation of In-Situ gel.
\end{abstract}

Keywords: Nasal Drug Delivery, In Situ gel, gelation, polymers, etc

Article Info: Received 27 Jan 2020; Review Completed 20 March 2020; Accepted 27 March 2020; Available online 15 April 2020

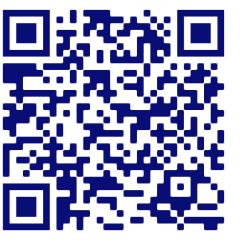

Cite this article as:

Sabale A, Kulkarni A, Sabale A, Nasal In Situ Gel: Novel Approach for Nasal Drug Delivery, Journal of Drug Delivery and Therapeutics. 2020; 10(2-s):183-197 http://dx.doi.org/10.22270/jddt.v10i2-s.4029

*Address for Correspondence:

Dr. Abhijeet Kulkarni, Department of Pharmaceutical Quality Assurance, Sanjivani College of Pharmaceutical Education and Research, Kopargaon, Maharashtra-423601, India

\section{INTRODUCTION}

The nasal route is an important mode of drug delivery, with a growing number of products available for administration through the route for systemic and local administration. An in-situ gel is a new dosage form. In situ gel has been applied in nasal drug delivery recently.

Compared with other liquid nasal formulation nasal in-situ gels are administered as low viscosity solution into the intranasal cavity which upon contact with the nasal mucosa, the polymer changes conformation making a gel. So that it not only increases the contact time between the drug and the absorptive site but also releases the drug slowly in the nasal cavity.

A gel is a state between liquid and solid, which consists of physically cross-linked networks of long polymer molecules, with liquid molecules trapped within a three-dimensional polymeric network swollen by a solvent. Before administration, the in-situ gelling system is a liquid aqueous solution and it changes into a gel at the physiological condition. Prolonged and sustained release of the drug is reproducible, and in-situ gel is biocompatible, with magnificent stability and reliable quantities of medication, making it more accurate.

There are various routes for in situ gel drug delivery, for, example, oral, ocular, vaginal, rectal, intravenous, intraperitoneal, etc. Gelation happens through crosslinking of the polymer chain, which can be attained through covalent bond formation (chemical crosslinking) or non-covalent bond formation (physical crosslinking). A different mechanism exists which produce the formation of in-situ gels, like depend on physiologic stimuli (e.g. temperature modifications, pH-triggered systems), those based on physical changes in biomaterials (e.g. Solvent exchange and swelling), and those depend on chemical reactions (e.g. UV radiation, ionic crosslinking and ion activated systems). In this system, there is no need for any organic solvents, 
copolymerization agents, or a directly applied trigger for gelation. In-situ gel formulation is carried out for targeted delivery through the vaginal and rectal routes, and the nasal mucosa, circumventing the hepatic first-pass metabolism, which is important for the proteins and peptides delivery that is usually administered via the intravenous route because of their susceptibility to the gastrointestinal protease.(1)(2)

\section{NASAL DRUG DELIVERY SYSTEM}

Intranasal delivery mainly offers potentially an alternative viable for various drug delivery. It is suitable for the local and systemic delivery of diverse therapeutic compounds. Hence there have been many investigations involving the nasal cavity as a feasible site for the administration of many therapeutic agents. It is effective in the treatment of local, systematic and CNS sites.

Local: Intranasal administration of medicines is the natural choice for the treatment of topical nasal Disorders. Among the most common examples are antihistamines and corticosteroids for rhinosinusitis, and nasal decongestants for cold symptoms. In these cases, the intranasal route is the primary option for drug delivery because it allows a rapid symptom relief with less side-effect.

Systemic: The intranasal administration is an effective way to systemically deliver drugs as an alternative to oral and intravascular routes. Consequently, by nasal formulations, the number of drugs administered intended to achieve systemic effects has widely increased. Some prominent examples include analgesics [morphine], cardiovascular drugs as Propranolol and carvedilol, hormones such as levonorgestrel, progesterone and insulin, anti-inflammatory agents as indomethacin and Ketorolac, and antiviral drugs [acyclovir]. (2)

\section{ANATOMY AND PHYSIOLOGY OF NOSE}

It is essential to have a clear understanding of the anatomy and physiology of the nose and how it relates to the characteristics of the delivery system used. In humans and other animal species, the major functions of the nasal cavity are breathing and olfaction. It also affords an important protective activity once it filters, heat and humidifies the inhaled air before reaching the lowest airways. The human nasal cavity has a total volume of $15-20 \mathrm{ml}$ and a total surface area of approximately $150 \mathrm{~cm}$. The nose is separated in two nasal cavities by the septum. The volume of each cavity is about $7.5 \mathrm{ml}$ and has a surface area around $75 \mathrm{~cm} \mathrm{pH}$ of the mucosal secretions ranges from 5.0 to 6.7 in children and 5.5 to 6.5 in adults. The nasal passage epithelium is covered by a mucus layer that is renewed every 10 to $15 \mathrm{~min}$. From the nose, mucus moves at a rate of 5 to $6 \mathrm{~mm} / \mathrm{min}$ resulting in particle clearance within the nose every $20 \mathrm{~min}$. (2)

\section{Three regions can be distinguished in each part}

1. Respiratory region: The nasal respiratory region is the largest part of the nasal cavity, also called conchae. The respiratory region is the most important for systemic drug delivery.10-12 The respiratory epithelium is composed of four types of cells, namely, non-ciliated and ciliated columnar cells, basal cells and goblet cells. The respiratory region contains three nasal turbinates: superior, middle, and inferior which project from the lateral wall of each of the nasal cavity. For systemic drug delivery, nasal respiratory mucosa is considered the most important section.

2. Vestibular region: Most anterior part of the nasal cavity is nasal vestibule, just inside the nostrils, and presents an area about $0.6 \mathrm{~cm}$ this nasal portion is covered by a stratified squamous and keratinized epithelium with sebaceous glands is responsible for filtering out the airborne particles. It is considered to be less important in the three regions concerning drug absorption.

3. Olfactory region: The olfactory region is located in the roof of the nasal cavity and extends a short way down the septum and lateral wall it is of about $10 \mathrm{~cm} 2$ in surface area and it plays a vital role in the transportation of drugs to the brain and the CSF. When the drug is administered by the nasal route, it can enter into the brain by three different paths. The first one is the systemic path, by this route the drug is absorbed into the systemic circulation and subsequently reaches the brain by crossing BBB [especially lipophilic drug]. The other pathways are the olfactory region and the trigeminal neural pathway by which the drug is directly transported from the nasal cavity to CNS [cerebrospinal fluid and brain tissue]. There is a different mechanism by which the drugs across the olfactory membrane reach CNS. The first mechanism involves a direct transfer of the drug to primary neurons of the olfactory epithelium and transport to the olfactory bulb by intracellular axonal transport with subsequent possible distribution into more distant brain tissues. The second mechanism depends on the drug permeation across the olfactory sustentacular epithelial cells, either by transcellular or paracellular mechanisms followed by uptake into CNS. The last one employs pinocytosis by olfactory neurons. (1)(3)

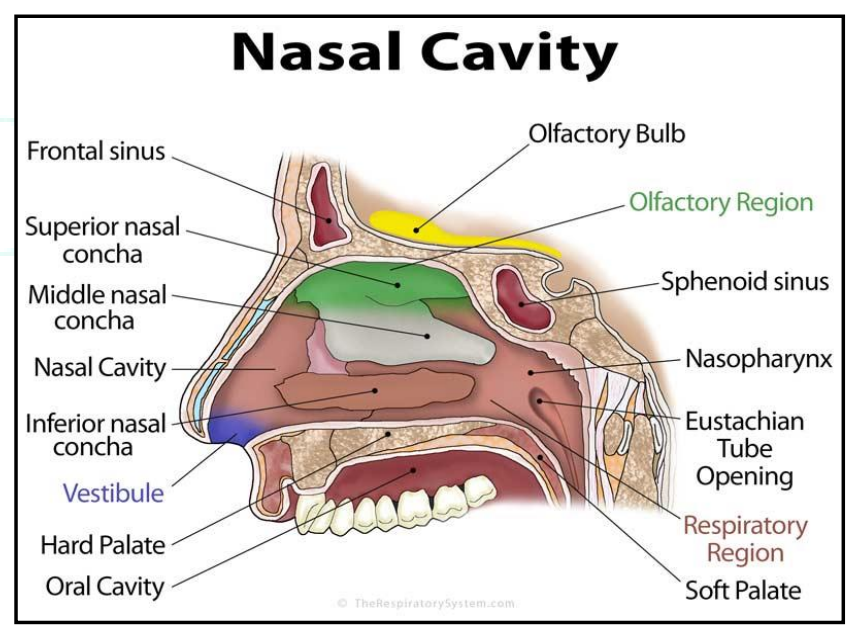

Figure 1: Anatomy And Physiology of Nose 


\section{ADVANTAGES (ASSOCIATED FACTORS) OF INTRANASAL DELIVER}

Table 1: Advantages of intranasal delivery (4)(5)(2)

\begin{tabular}{|c|c|}
\hline Advantages & Factors \\
\hline $\begin{array}{l}\text { Improving patient } \\
\text { compliance and convenience }\end{array}$ & $\begin{array}{l}\text { A trained person not required } \\
\text { Needle-free (painless) } \\
\text { Non-invasive } \\
\text { User-friendly } \\
\text { Ease of administration } \\
\text { Self-medication possible } \\
\text { The nasal route is suitable when compared with a parenteral route for long term therapy } \\
\text { Minimal aftertaste } \\
\text { The risk of transmission of infectious disease is reduces }\end{array}$ \\
\hline $\begin{array}{l}\text { Rapid absorption and onset } \\
\text { of pharmacologic action }\end{array}$ & $\begin{array}{l}\text { Highly vascularized mucosa } \\
\text { Easy accessibility to blood capillaries } \\
\text { Large nasal mucosal surface area } \\
\text { Drugs which cannot be absorbed orally may be delivered by nasal route direct in the } \\
\text { systemic circulation }\end{array}$ \\
\hline Good penetration & $\begin{array}{l}\text { For lipophilic drugs } \\
\text { For low molecular weight drugs } \\
\text { Bioavailability of larger drug molecules can be increased using absorption enhancer or } \\
\text { other approaches }\end{array}$ \\
\hline $\begin{array}{l}\text { Direct delivery of a drug to } \\
\text { CNS system }\end{array}$ & $\begin{array}{l}\text { Bypass BBB, via olfactory region } \\
\text { Useful for local and systemic delivery }\end{array}$ \\
\hline Avoids a harsh environment & Less chemical and enzymatic degradation \\
\hline Low dose required & $\begin{array}{l}\text { Drug degradation is absent. } \\
\text { Avoids the first-pass metabolism } \\
\text { Avoids GIT degradation } \\
\text { Lower side effects } \\
\text { High bioavailability }\end{array}$ \\
\hline
\end{tabular}

\section{LIMITATIONS (ASSOCIATED FACTORS) OF INTRANASAL DELIVERY (4)(5)(2)}

Table 2: Limitations of intranasal delivery

\begin{tabular}{|l|l|}
\hline Limitation & Factors \\
\hline $\begin{array}{l}\text { Reduced capacity of nasal absorption means low } \\
\text { bioavailability }\end{array}$ & $\begin{array}{l}\text { Due to pathologic conditions such as cold or allergies, } \\
\text { which may significantly alter the nasal bioavailability } \\
\text { Lack of adequate aqueous solubility. }\end{array}$ \\
\hline $\begin{array}{l}\text { Sometimes, the drugs cause irritation and irreversible } \\
\text { damage of the cilia on the nasal mucosa }\end{array}$ & Due to constituents added in dosage forms \\
\hline $\begin{array}{l}\text { Defense mechanisms such as mucociliary clearance } \\
\text { influence permeability of drug }\end{array}$ & An enzymatic barrier to the permeability of drug \\
\hline Disrupt and dissolve the nasal membrane & Due to the high concentration of absorption enhancers \\
\hline $\begin{array}{l}\text { High molecular weight compounds cannot be supplied } \\
\text { (mass cut off - } 1 \text { kDa) }\end{array}$ & $\begin{array}{l}\text { The volume of 25-200 ml that can be distributed into the } \\
\text { nasal cavity is inadequate }\end{array}$ \\
\hline Irreversible administration & Once the drug administered cannot be removed \\
\hline
\end{tabular}




\section{BARRIERS FOR NASAL DRUG DELIVERY}

Major barriers to nasal drug delivery are low bioavailability, mucociliary clearances, and enzyme degradation. Some important characteristics of different barriers which affect the nasal drug delivery are discussed below:

\section{Low bioavailability:}

- Bioavailability of polar drugs is fundamentally low (about $10 \%$ for low molecular weight drugs and $1 \%$ for peptides, for example, calcitonin and insulin).

- Polar drugs have limited nasal absorption with large molecular weight.z

- Drugs can cross the epithelial cell membrane by the transcellular and paracellular routes between cells.

- Polar drugs with a molecular weight below 1000 Da will pass the membrane by the latter routes.

- Nasal absorption of polar drugs is enhanced by the coadministration of absorption-enhancing agents.

- Polarity lipophilic:

1. LMW lipophilic $-100 \%$ bioavailability

2. HMW amphipathic $-10 \%$ bioavailability

3. Peptides $<1 \%$

Examples

- Surfactants (Sodium lauryl sulfate, sodium dodecyl sulfate, phosphatidylcholines, Laureth-9)

- Bile salts (Sodium glycocholate, sodium taurocholate, sodium deoxycholate)

- $\quad$ Fatty acids and their derivatives (linoleic acid)

- Phospholipids (lysophosphatidylcholine)

- Various cyclodextrin and cationic compounds like chitosan, poly-L-arginine, and poly-L-lysine

- Fusidic acid derivatives (sodium tauradihydrofusidate)

Mucociliary clearance:

- It is an important factor that involves in both combine action of mucus and cilia, which fight against inhaled foreign particles in the respiratory tract.
- Drug transportation across the nasal mucosa leads to decreases because of high clearance.

- For liquid and powder formulation which are not bioadhesive, the half-life for clearance is of the order of 15-30 min.

- To overcome the rapid mucociliary clearance bioadhesive excipients are used in the formulation.

- The clearance may also be decreased by retaining the formulation in the anterior and less ciliated part of the nasal cavity, thus leading to improved absorption.

\section{Enzymatic degradation:}

- When peptides and proteins cross the nasal mucosa, there are chances of enzymatic degradation of the molecule in the lumen of the nasal cavity or during passage through the epithelial barrier, which can limit the bioavailability of the drug.

- These two sites contain exopeptidases such as mono and diamino peptidases that can cleave peptides at their $\mathrm{N}$ and $\mathrm{C}$ termini, and endopeptidases like serine and cysteine, which can attack internal peptide bonds. The use of enzyme inhibitors, cosolvents, and prodrugs may be the way to overcome this barrier.(4)

\section{IDEAL DRUG CANDIDATE FOR NASAL DRUG DELIVERY}

- The drug should not produces any irritation to the nasal mucosa

- The drug should not cause any side effect

- The drug should not contain any toxic metabolites

- The drug should be free from any offensive odor

- A dose of the drug should be less than $25 \mathrm{mg}$

- The drug should puses appropriate nasal absorption property

- $\quad$ Suitable clinical rationale for a nasal dosage form

- $\quad$ Suitably stable characteristics (2)(6)

\section{PROFILE OF AN IDEAL DRUG CANDIDATE SUITABLE FOR NASAL DRUG DELIVERY SYSTEM (7)}

Profile of an ideal drug candidate for nasal drug delivery
Dolecular weight $<500 \mathrm{Da}, \log \mathrm{P}<5$
Dose potency $<5 \mathrm{mg} / \mathrm{dose} / \mathrm{spray}$ of puff per nostril
No nasAal irritation from drug
No toxic metabolites
Volume $25-125 \mu \mathrm{l}$ per nostril

Figure2. Profile of an ideal drug candidate suitable for nasal drug delivery System 


\section{MECHANISM OF DRUG ABSORPTION:}

The absorption of the drug from a nasal route for systemic or CNS effect occurs when it passes through the mucous layers and epithelial membrane before reaching the systemic circulation or passes directly to CNS. For systemic effect, drug absorption is considered to take place in the respiratory region consisting of turbinates and part of the nasal septum. The olfactory region, which is next to the respiratory region, is the foremost site from where the drug can be absorbed directly into the brain for the CNS effects. When a drug is given intranasally, a drug can directly reach the brain either by direct transport from olfactory region to the brain or from the blood (systemic circulation) to the brain or through the trigeminal neural pathway by which drug partly travels from the nasal cavity to the cerebrospinal fluid (CSF). Consequently, the olfactory region of the nasal mucosa that provides a direct connection between nose and brain which can be exploited for targeting of drug molecules acting on CNS in conditions like Alzheimer's disease, Parkinson's disease, depression, migraine, schizophrenia, epilepsy, brain tumors, psychosis, and pain. The absorbed drugs must pass from the nasal cavity to the mucus layer. This is the initial step of absorption. The drug with small particle size can easily pass through this mucus layer but larger, charged drug is difficult to pass it. Mucin is the main principle protein of the mucus, which tends to bind to the solute, hindering the diffusion. In the mucous layer, some additional structural changes are possible as a result of changes in environment like $\mathrm{pH}$, temperature. Drug absorption through the mucosa has a different mechanism. They include transcellular (simple diffusion across the membrane) and paracellular transport (movement between cell and transcytosis by vesicle carriers). Drug absorbed can potentially be metabolized before reaching the systemic circulation and has a limited residence time in the cavity. Different mechanisms, such as passive diffusion (transcellular), passive diffusion (paracellular), carriermediated transport, transcytosis, absorption, and efflux transport have been used for drug transport through the nasal epithelium. Table III discusses some important comparisons between the two mechanisms, which are widely used in drug transport through the nasal epithelium. $(4)(7)(1)$

Table 3: Mechanism of drug passage through the mucus.

\begin{tabular}{|c|c|}
\hline First mechanism (Paracellular process) & Second mechanism (Transcellular process) \\
\hline $\begin{array}{l}\text { - Aqueous route of transport. } \\
\text { - The process occurs within the cell and transcytosis by } \\
\text { vesicle carrier } \\
\text { - This route is slow-moving and passive } \\
\text { - It is suited for hydrophilic drugs } \\
\text { - There is an inverse log-log correlation in between intranasal } \\
\text { absorption and the molecular weight of water-soluble } \\
\text { compounds } \\
\text { - Bio-availability of drugs was observed poor with a } \\
\text { molecular weightgreater than } 1000 \text { Daltons. }\end{array}$ & $\begin{array}{l}\text { - Lipoidal route of transport } \\
\text { - By an active transport route, drugs can also cross the } \\
\text { cell membranes with carrier-mediated transport } \\
\text { through the openings of tight junctions } \\
\text { - It is a means of the transport of lipophilic } \\
\text { drugs that show a rate-dependency on their lipophilicity } \\
\text { - For example, chitosan, a natural biopolymer, opens } \\
\text { tight junctions between epithelial cells to facilitate drug } \\
\text { transport. }\end{array}$ \\
\hline
\end{tabular}

\section{FACTORS AFFECTING NASAL DRUG DELIVERY SYSTEM}

\section{Physiochemical properties of a drug}

a) Molecular weight: Nasal delivery of a is expected to decrease with an increasing molecular weight of the drug molecule. A linear inverse correlation within the absorption of drugs and the molecular weight of the drug has been reported and the molecular weight of the drug is greater than $1000 \mathrm{Da}$ except by using of absorption enhancers. With the use of permeation enhancers, good bioavability to at least 6000 Daltons can be achieved. (2)

b) Chemical form: It is an important factor for drug absorption. By changing the drug into salt or an ester form can change its absorption; e.g. in situ absorption of carboxylic acid esters of L-tyrosine was significantly greater than that of unmodified L-Tyrosine. (4)

c) Size: Particle size and morphology of a drug are important tools for the design of nasal drug delivery. Generally, particles in the 5-10 microns range should be deposited in the nostrils. Too fine particles, less than five microns may be inhaled into lungs and should be avoided for nasal products while particles greater then $10 \mu \mathrm{m}$ are deposited with the upper respiratory tract. (2) d) Solubility: Solubility is not only limited the drug absorption, but it can also limit a formulator"s ability to formulate a formulation if the drug is not sufficiently soluble in the desired vehicles. From a mechanistic and thermodynamic standpoint of view, it is important to learn about the relationship between a drug's saturation solubility and its absorption.(2)

e) Lipophilicity: Lipophilic compounds tend to readily cross biological membranes via the transcellular route and these compounds can partition into the lipid (bilayer) of the cell membrane and diffuse into and traverse the cell in the cell cytoplasm. Some examples of lipophilic drugs like naloxone, buprenorphine, testosterone, and 17a-ethinylestradiol, are completely or almost completely absorbed by the nasal route in animal models. The permeation of the compound normally increases through nasal mucosa by increasing lipophilicity. (2)

f) Pka and partition coefficient: According to the $\mathrm{pH}$ partition theory, unionized species are absorbed better compared with ionized species and the same holds in the case of nasal absorption.(2)

g) Polymorphism: It can affect the rate of drug dissolution, solubility, and absorption through biological membranes. (4) 


\section{Physicochemical properties of a formulation}

a) Drug concentration, dose, and dose-volume: Drug concentration, dose, and dose-volume of administration are three interlinked parameters that affect the performance of the nasal delivery system. If the drug concentration formulation is increasing by increasing formulation volume there may be a limit as to what extent nasal absorption will drain out of the nasal cavity. $0.05-0.15 \mathrm{ml}$ is the ideal dose volume with an upper limit of $0.20 \mathrm{ml} .(2)$

b) pH and mucosal irritation: In addition to the properties of the nasal surface, the $\mathrm{pH}$ of the formulation can affect a drug's permeation. Both the $\mathrm{pH}$ and $\mathrm{pKa}$ of a drug are considered to rationalize systemic absorption. To avoid nasal irritation, the $\mathrm{pH}$ of the nasal formulation should be adjusted to 4.5-6.5. By avoiding nasal irritation results in obtaining an increase in drug permeation and prevents the growth of bacteria. Nasal secretions contain lysozyme, which destroys certain bacteria at acidic $\mathrm{pH}$. Lysozyme is inactivated and the nasal tissue is susceptible to microbial infection under alkaline conditions. (4)

c) Buffer capacity: Nasal formulations are administered in little volumes ranging from 25 to $200 \mu \mathrm{L}$. Hence, nasal secretions may change the $\mathrm{pH}$ of the administrated dose. This can affects the concentration of unionized drugs available for the absorption. Therefore, an appropriate formulation buffer capacity may be required to maintain the pH in-situ. (2)

d) Solubilizers: Aqueous solubility of the drug is always a limitation for nasal drug delivery in solution. Co-solvents are used for increasing solubility like glycols, alcohol, Transcutol, medium-chain glycerides and Labrasol can be used to enhance the solubility of drugs. (2)

e) Preservatives: Nasal formulations mostly contain preservatives to protect them from microbial contamination. Some generally used preservatives are parabens, benzalkonium chloride, and benzoyl alcohol. Preservatives are used in small quantities and are not likely to affect drug absorption (2)

f) Antioxidants: Antioxidants have not any effect on drug absorption or cause nasal irritation. Example- sodium metabisulfite, sodium bisulfate, butylated hydroxyltoluene, and tocopherol. (2)

g) Humectants: Intranasal moisture is important for preventing dehydration. Therefore, humectants can be added mostly in gel-based nasal products to avoid irritation of the nasal cavity. Humectants do not affect drug absorption. Examples like glycerin, sorbitol, and mannitol. (2)

h) Absorption enhancer: Absorption enhancers could also be needed when a drug has poor membrane permeability, large molecular size, lack of lipophilicity and enzymatic degradation. Once a suitable enhancer is identified, its optimal concentration should be experimentally determined. Generally, higher concentrations of absorption enhancers are probable to result in nasal irritation and damage to the nasal mucosa. On the other hand, lower enhancer concentrations would generally provide lower or no improvement of absorption. (2)

i) Osmolarity: Isotonic solutions are administered for shrinkage of the nasal epithelial mucosa, because of the effect of osmolarity on the absorption, this results in increased permeation of the compound because of structural changes in the compound. Isotonic solutions also are known to inhibit ciliary activity. (4)

j) Viscosity: The higher viscosity of the formulation increases contact time between the drug and therefore the nasal mucosa, thereby increasing permeation time. At the same time, formulations with high viscosity can affect the normal functions like ciliary beating or muco-ciliary clearance and thus changes the permeability of drugs. (4)

\section{Physiological factors}

a) Blood flow/ supply: Nasal mucosa has a larger surface area and rich with blood supply which makes nasal an optimum place for drug absorption. The blood flow influences significantly the systemic nasal absorption of the medicine so that because it enhances more drug passes through the membrane, reaching the overall circulation.(2)

b) Nasal secretion: The mucus layer probably exists as a double layer ( $5 \mathrm{~mm}$ thick) consisting of a periciliary sol phase in which the cilia beat and a superficial blanket of gel are moved forwards by the tip of the cilia. The permeability of drug through the nasal mucosa is suffering from viscosity of nasal secretion. Approximately 1.5-2.1 ml of mucus is produced daily in the nasal cavity. It is reported that if the sol layer of mucus is too thin, the viscous surface layer will inhibit the ciliary beating, and if the sol layer is too thick, mucociliary clearance is impaired because contact with cilia is lost. The solubility of a drug in nasal secretions: a drug needs to be solubilized before it permeates. Various studies revealed that the secretion ad clearance rates are reduce d at night thus altering the permeation of drug. In such cases, chronokinetics will dictate the pattern and rate of permeation. (2)

c) Nasal cycle: In this process congestion and relaxation regulate the rise and fall in the amount of drug permeation process. (2)

d) $\mathbf{A} \mathbf{~ p H}$ of the nasal cavity: Nasal cavity $\mathrm{pH}$ in the adult is 5.5-6.5 and 5.0-7.0 in infants. A greater drug permeation is usually achieved at a nasal $\mathrm{pH}$ that is lower than the drug"s $\mathrm{pKa}$ because under such conditions the penetrant molecules exist as unionized form. A change in the $\mathrm{pH}$ of mucus can affect the ionization and thus increase or decrease the permeation of drugs, depending on the nature of the drug. The ideal $\mathrm{pH}$ of a formulation should be within 4.5-6.5 and if possible the formulation should also have the buffering capacity. (2)

e) Effect of mucociliary clearance: The main function of the mucociliary clearance system is to remove foreign substances (bacteria, allergens and so on) and particles from the nasal cavity, thus preventing them from reaching the lower airways. Normal mucociliary transit has been reported to be 12 to $15 \mathrm{~min}$. Transit times of more than $30 \mathrm{~min}$ are considered to be abnormal and are indicative of impaired mucociliary clearance. Reduced Mucociliary clearance (MCC) and ciliary beating (MCC) increases the time of contact between a drug and the mucous membrane and subsequently enhances drug permeation; whereas, increased MCC decreases drug permeation. Some factors affecting MCC like drugs, hormonal changes of the body, pathological conditions, environmental conditions, and formulation factors.(4) 
f) Effect of deposition on absorption: Deposition of the formulation in the anterior portion of the nose provides an extended nasal residence and better absorption, and this is an area of low permeability, whereas, in the posterior portion of the nose, where the drug permeability is generally higher, the deposited drug is eliminated by mucociliary clearance and therefore has a shorter residence time. (4)

g) Effect of enzymatic activity: Many enzymes might affect the stability of drugs that are present on the nasal mucosa. For example, proteins and peptides are subjected to degradation by proteases and aminopeptidases at the mucosal membrane. (4)

4. Biological Factors: Efforts have been made to modify and explore the structural features and mechanism of nasal mucosa to increase its permeability, this is usually not available in the normal physiology of the nasal cavity, mainly during chronic application. These alterations could cause unintended adverse effects and result in pathological implications.

a) Structural features: Nasal epithelium mainly consists of different types of cells that show variety in nasal absorption and because of other factors such as presences of microvilli, cell density, surface area, and several cells. The respiratory region is most accurate and suitable for permeation of the compounds.(2)

b) Biochemical changes: A large number of enzymes such as oxidative and conjugative enzymes, peptidases and proteases are mainly acted on nasal mucus which is an enzymatic barrier for the delivery of drugs. These enzymes are responsible for the degradation of drugs in the nasal mucosa and result in the creation of a pseudofirst-pass effect, which hampers the absorption of drugs. Some example like the nasal P450-dependent monooxygenase system has been implicated in nasal metabolism of nasal decongestants, alcohols, nicotine, and cocaine.(2)

5. Pathological condition: Diseases such as the common cold, rhinitis, atopic rhinitis and nasal polyposis are usually associated with mucociliary dysfunctioning, hypo or hypersecretions, and irritation of the nasal mucosa, which can influence drug permeation.

a) Environmental condition: Temperatures in the range of $24^{\circ} \mathrm{C}$ cause a moderate reduction in the rate of MCC. A linear increase in ciliary beat frequency occurs with an increase in temperature, which in turn influences the properties of the mucous membrane. (4)

\section{DIFFERENT METHODS TO IMPROVE NASAL ABSORPTION}

1) Permeation enhancers: $A$ variety of permeation enhancers have been investigated to improve the nasal absorption, like fatty acids, bile salts, phospholipids, surfactants, cyclodextrin, etc., which act via different mechanisms such as inhibition of enzyme activity, reduction of mucus viscosity, decreasing muco-ciliary clearance, opening tight junctions, and solubilizing or stabilizing the drug.

2) Prodrug approach: Prodrugs are the inactive chemical moiety that becomes active at the target site. This approach is mainly used to improve physicochemical properties such as taste, solubility, and stability of the formulation. This approach includes the derivatization of $\mathrm{C}$ and $\mathrm{N}$ termini, esters, and cyclic prodrugs.

3) In situ gel: The conversion into a gel by the influence of stimuli including temperature, $\mathrm{pH}$, and ionic concentration, is possible with substances like Carbopol, cellulose derivatives, lecithin, chitosan, etc. These formulations generally control the problems of administration.

4) Nasal enzyme inhibitors: Enzyme inhibitors like protease and peptidase are used as inhibitors for the formulation of peptide and protein molecules. Other examples are bile salts, amastatin, bestatin, boroleucine, fusidic acids, etc.

5) Structural modification: Drug structure can be modified without changing the pharmacologic activity, to improve nasal absorption. Chemical modifications are mainly used to modify the physicochemical properties of the drug such that they lead to improved nasal absorption of the drug.

6) Mucoadhesion: Mucoadhesion is defined as the state in which two materials are held together for a long period. Mucoadhesive polymers make contact with the biological membrane, and after the establishment of contact, they penetrate the tissue surface. Natural polymers can be easily obtained from natural sources, and require an environmentally- friendly method of processing at a low cost. Some examples include potato starch, rice starch, maize starch, wheat starch, guar gum, tragacanth, xanthan gum, etc. Synthetic polymers have high cost of production and also produce environmental pollution during synthesis. These polymers include polyethylene oxide, polyvinyl alcohol, methylcellulose, ethylcellulose, hydroxyl propylmethylcellulose, etc. (4)

\section{INTRANASAL FORMULATIONS AND THEIR LIMITATIONS}

A myriad of intranasal formulations is available that include nasal drops, solution sprays, suspension sprays, emulsions, powders, ointments, gels, liposomes, microspheres, and nanoparticles. These non-mucoadhesive formulations administered in a limited volume of $25-200 \mu \mathrm{l}$ exhibit short residence time due to mucociliary clearance. Consequently, the half-life of clearance for both liquid and powder formulations is of the order of $15-30 \mathrm{~min}$. This is mainly due to the mucus which moves through the nose at a rate of 5-6 $\mathrm{mm} / \mathrm{min}$ resulting in particle clearance within the nose, about every 12-15 min. This limits the time available for drug absorption from the applied dosage form and results in poor nasal bioavailability. To prevent rapid mucociliary clearance and improve the bioavailability of drugs, there is a persistent need for the development of the controlledrelease delivery system. Mucoadhesive nasal drug delivery systems can be looked on as a viable option that can adhere to the nasal mucosa, will increase the residence time within the nasal cavity, intensify the contact between the nasal mucosa and the drug, increase the drug concentration at the site of deposition and facilitate drug absorption to enhance bioavailability. (4)(7) 


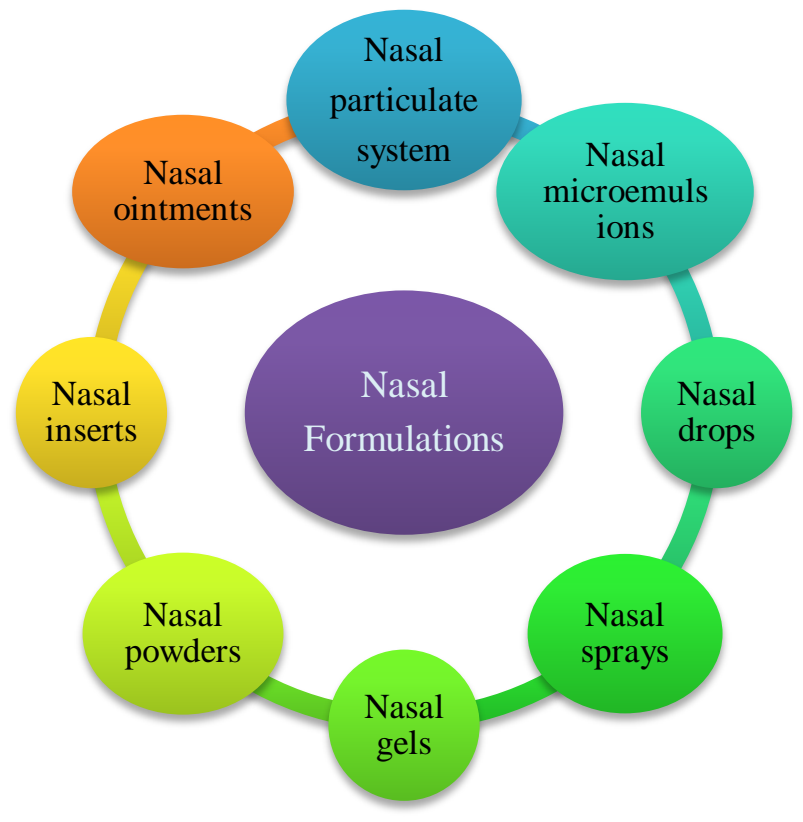

Figure 3: Various forms of nasal formulations.

\section{THE ADVANTAGES OF IN SITU NASAL GELS OVER OTHER NASAL FORMULATIONS INCLUDE:}

- $\quad$ Reduction in post-nasal drip into the back of the throat and therefore minimization of bad taste problems and loss of drug from the nasal cavity.

- Reduction in anterior leakage of the drug out of the nasal cavity.

- Localization of formulation on the mucosa thereby providing a better chance for the drug to be absorbed.

- Gels can afford the use of soothing agents or emollients which may not be suitable for solutions, suspensions or powder dosage form so can reduce irritation potential.

- It can be developed for both systemic and local delivery, and a precise dose can be administered by the use of a metered-dose nasal actuator system.

- Prolong drug release

- $\quad$ Reduced systemic side effect

- Reduced number of application

- $\quad$ Ease of administration

- Reduced frequency of administration

- $\quad$ Better patient compliance (5)(7)

\section{IN SITU GEL}

In Latin, in situ means 'in position' or 'in its original place'. For the past 30 years, greater attention has been directed towards the development of controlled and sustained drug delivery systems. A vast amount of research has been carried out in designing polymeric systems such as in situ gels. In situ gel formation of drug delivery systems can be defined as a liquid Formulationgenerating a solid or semisolid depot after administration. In situ activated gel, forming Systems are those which are when exposed to physiological conditions that will shift to a gel phase. This new concept of manufacturing a gel in situ was suggested for the first time in the early 1980s. Gelation occurs via the cross-linking of polymer chains that can be achieved by covalent bond formation (chemical cross-linking) or
Non-covalent bond formation (physical cross-linking). The routes of administration for in situ gel could be oral, ocular, rectal, vaginal, injectable and intra-peritoneal. "Gel" is that the state which exists in between liquid and solid, which consists of physically crosslinked networks of long polymer molecules, with liquid molecules trapped within a three-dimensional polymeric network swollen by a solvent. This system is a liquid aqueous solution before the administration and a gel at physiological conditions. Prolonged and sustained release of the drug is reproducible, and the in situ gel is biocompatible, with magnificent stability and reliable quantities of medication, making it more accurate. There are various routes for in situ gel drug delivery, for example, oral, ocular, vaginal, rectal, intravenous, intraperitoneal, etc. In situ gel is a new dosage form that has been applied in nasal drug delivery recently. Compared with other liquid nasal formulations, nasal in situ gels are administered as low viscosity solutions into the nasal cavity, and upon contact with the nasal mucosa, the polymer changes conformation producing a gel, so it cannot only prolong the contact time between the drug and also the absorptive sites within the cavity but also release drug slowly and continuously, hence, it's especially useful for those drugs used chronically. The phase transition can be induced by a shift in $\mathrm{pH}$, a shift in temperature or by the presence of cations. (4)(5)(8)

\section{IMPORTANCE OF IN SITU GELLING SYSTEM}

The major importance is that the possibility of administering accurate and reproducible quantities compared to already formed gel. It increases the exposure time of drugs with that of mucus at the site of absorption and has better bioavailability, increases patient compliance. (4)

\section{PRINCIPLE OF IN SITU GELLING SYSTEM}

The principle of in situ gelling system is of solid nasal formulations are that the nasal formulations absorb the nasal fluid after administration and form a gel within the cavity. The foreign body sensation can avoid by the formation of nasal gel within the cavity. Due to bioadhesive nature, the gel adheres to the nasal mucosa. It acts as a release controlling matrix and thus acts as a sustained drug delivery system. In the nose, the mucus lower layer comes 
and goes around the cilia, forward in the propulsion phase, backward in the preparatory phase. At the propulsion phase, cilia extremity scrapes the upper layer of mucus penetrating it almost $0.5 \mathrm{~mm}$. ciliary activity zones then occur at various intervals. Cilia are situated backward which helps to remove any obstacle if there is any intervention in the propulsion phase. After the formation of the gel, dissolution occurs and or the mucociliary removal to the nasopharynx occurs. Therefore there is no need to remove the dosage form after it has been depleted of a drug. (4)(9)

\section{PROPERTIES OF NASAL IN- SITU GEL}

- It should have a long residence time.

- It should be low viscous.

- Free-flowing allows for reproducible administration to the nasal cavity.

- The nasal in-situ gel follows the phase transition mechanism and shear forces in nasal cavity wall. (10)

\section{APPROACHES OF IN-SITU GELLING SYSTEM:}

Various approaches for an in-situ gelling system,

A) Stimuli Responsive In-Situ Gelling System

1. Temperature induced in-situ gel system.

2. $\mathrm{pH}$ induced in-situ gel systems.

B) Osmotically Induced In-Situ Gelling System

C) Chemically Induced In-Situ Gelling System

1. Ionic cross linking.

2. Enzymatic cross linking.

3. Photo- polymerization.

D)In situ formation based on the physical mechanism-

\section{A) Stimuli Responsive In-Situ Gelling System}

Physical or chemical changes in response to small external changes in the environmental conditions

\section{Temperature induced in-situ gel system:}

Temperature is the most generally used stimulus in environmentally responsive polymer systems. The change of temperature isn't only relatively easy to regulate, but also easily applicable both in-vivo and in-vitro. These insitu gelling systems are liquid at temperature $\left(20^{\circ}-25^{\circ} \mathrm{C}\right)$ and further undergoes gelation when it comes in contact with body fluids $\left(35^{\circ}-37^{\circ} \mathrm{C}\right)$ because of an increase in temperature. Polymers like poloxamers or pluronics, cellulose derivatives (methylcellulose, HPMC, ethyl (hydroxyl ethyl) cellulose (EHEC) and xyloglucan show temperature induced gelation.

The ambient and physiologic temperature is the important temperature range for such a system, such that experimental management is facilitated and for gelation there is no requirement of an external source of heat. A temperature sensitive in situ gel undergoes a sol-gel phase transition at a critical temperature, specifically at the lower critical solution temperature (LCST) or upper critical solution temperature (UCST). LCST polymers form a hydrophilic-to-hydrophobic transition with the increasing temperature. LCST polymers include poly ( $\mathrm{N}$-isopropyl acrylamide), poly ( $\mathrm{N}, \mathrm{N}$-dimethy acrylamide), poly(vinyl ether), poly(N-vinylalkylamide), polyphosphazene derivatives, and poly(ethylene oxide)-bpoly(propylene oxide). UCST polymers show a hydrophobicto-hydrophilic transition with increasing temperature. UCST polymers include polyacrylamide/ polyacrylic acid interpenetrating polymer networks.

\section{2. pH-Triggered systems}

The $\mathrm{pH}$ is also another important environment-sensitive parameter for drug delivery, because the change in $\mathrm{pH}$ occurs at many specific sites or pathologic body sites, like the stomach, intestine, endosome, vagina, blood vessels, lysosome, and tumor extracellular sites. The polymers containing acidic or alkaline functional groups that respond to changes in $\mathrm{pH}$ are called $\mathrm{pH}$-sensitive polymers. All $\mathrm{pH}$ responsive polymers contain suspended acidic or basic groups that also accept or release protons in response to changes in environmental $\mathrm{pH}$. Polyelectrolytes are known as polymers with a large number of ionizable groups'. The $\mathrm{pH}$ is the main signal, which can be addressed through $\mathrm{pH}-$ responsive materials. Gelling of the solution is induced by a change in $\mathrm{pH}$. At $\mathrm{pH} 4.4$ the formulation is free from is a free running solution that undergoes coagulation when the $\mathrm{pH}$ is raised by the body fluid to $\mathrm{pH}$ 7.4. The polymers which show pH-induced gelation are cellulose and its derivatives polyvinyl acetate, polyethylene glycol. As the external $\mathrm{pH}$ increases, swelling of the hydrogel increases in the case of weakly acidic groups, but decreases when the polymer contains weakly (basic) groups. Examples: Anionic pHresponsive polymers are based on

-- Poly (acrylic acid), (Carbopol)

-- Polyvinyl acetal diethylaminoacetate solutions form hydrogels at a neutral $\mathrm{pH}$ condition at $\mathrm{pH} \mathrm{4,} \mathrm{with} \mathrm{a} \mathrm{low}$ viscosity.

-- Other examples are Polymethacrylic acid, Polyethylene glycol, Cellulose acetate phthalate latex, Pseudolatexes, etc

B) Osmotically Induced In-Situ Gelling System: In this system, gelling of the solution is triggered by changes in ionic strength. It is considered that the rate of gelation depends on the osmotic gradient across the surface of the gel. The aqueous solution of polymer forms a clear solution which forms a clear gel in the presence of cation like the mono or divalent cations. The polymer like gellan gum, alginates shows osmotically induced gelation.

C) Chemically Induced In-Situ Gelling System: The chemical reaction which forms in-situ gel systems are ionic crosslinking, enzymatic cross linking and photopolymerization

1. Ionic cross linking: Ion sensitive polymers like carrageenan, gellan gum, pectin, sodium alginate undergo phase change with the presence of various ions mainly like $\mathrm{k}+, \mathrm{Ca} 2+, \mathrm{Na}+$ ions. These polymers categorize into the class of ion-sensitive ones. For example, Alginic acid undergoes phase transition in the presence of divalent cations example$\mathrm{Ca} 2+$ because of the interaction with a guluronic acid block in alginate chains.

2. Enzymatic cross-linking: In-Situ formation catalyzed by natural enzymes has not been investigated widely but this system has some advantages over other approaches. For example, an enzymatic process performs effectively under physiologic conditions without the need for potentially harmful chemicals like monomers and initiators.

3. Photo polymerization: This system when introduced to the desired site with injection gets photocured in-situ with the help of fiber optic cables and then drug release for a prolonged period of time from the system. A photopolymerization, biodegradable hydrogels as a tissue contacting material and controlled release carrier. 
D) In situ formation based on the physical mechanism1. Swelling -

In situ formation can also occur when water absorbed by the material from the surrounding environment and expands to occur desired space. The substance like myverol 18-99 (glycerol monooleate), which contain polar lipid that swells in water to make lyotropic liquid crystalline phase structures. It has some bioadhesive properties and may be degraded invivo by enzymatic action.

\section{Diffusion-}

This method involves the diffusion of the solvent into the surrounding tissue from a polymer solution and leads to precipitation or solidification of the polymer matrix. $\mathrm{N}$ methyl pyrrolidone (NMP) solvent is beneficial for this type of system. (2)(5)(4)(6)(11)

\section{METHODS OF FORMULATION}

\section{Cold Method:}

In this method, the drug is stirred with a sufficient quantity of double distilled water and kept overnight at $4^{\circ} \mathrm{C}$ in a refrigerator. The in situ gelling polymers are then added slowly with stirring. The dispersion is stored in a refrigerator till a clear solution is formed and finally volume is adjusted with distilled water. This method is chosen when poloxamer, chitosan or carbopol is used as a gelling polymer. Considering the fact that polymeric dispersion of poloxamer is in solution at lower temperature and gets converted into a gel at higher nasal temperature because the solubility of polypropylene oxide chain of poloxamer decreases at a high temperature which results in precipitation or salting-out of a polymer. Similarly, chitosan also requires the low temperature to remain as a solution at room temperature, its hydrophobicity increases with an increase in temperature.(7)

\section{Hot Method:}

This method is used when gellan gum or pectin is used as a gelling polymer. At high temperature, gellan chains dissolve in water and assume a random-coil conformation with high segmental mobility at high temperatures and remain as a solution at a higher temperature. A phase transition occurs on a cooling gellan gum solution in the presence of ions like $\mathrm{K}+$ or $\mathrm{Ca} 2+$. Similarly, pectin also requires a high temperature for its demethoxylation, which helps in the formation of a solution or dissolving of pectin. (7)

\section{Other methods of preparation:}
A) Solution polymerization/cross linking
B) Suspension polymerization
C) Polymerization by irradiation
D) Chemically cross-linked hydrogels
E) Physically cross-linked hydrogels

\section{A) Solution Polymerization/Crosslinking}

Ionic monomer or neutral monomer and multifunctional crosslinking agents are mixed in the solution for copolymerization reaction. UV light or redox initiator system is used for thermally initiate the polymerization reaction. In the polymerization reaction, solvent work as a heat link, and decrease problems related to temperature control. Distilled water is used to remove the unreacted monomers, crosslinking agents and initiators which are used to form the hydrogels. By using this method one can synthesize a great different variety of in-situ gels.

\section{B) Suspension Polymerization}

Spherical hydrogel microparticles with a size range of $1 \mu \mathrm{m}$ to $1 \mathrm{~mm}$ are prepared by the suspension polymerization method. In the non-solvent solution, the monomer solution is dispersed to form fine droplets and a stabilizer is added in this solution to stabilize the fine droplets. Thermal decomposition of free radicals is used to initiate polymerization. Unreacted monomers, crosslinking agents and initiators are removed by washing from prepared microparticles. This method is used to prepare the hydrogel microparticles of polyvinyl alcohol.

\section{c) Polymerization by Irradiation}

Hydrogels of unsaturated compounds are formed by using high energy radiation like gamma and electron beams. Radicals on the polymer chain are formed by irradiation of aqueous polymer solution. Covalent bonds are formed by the recombination of the macroparticles on the different chains and thus forms a cross-linked structure. Polymerization of macroparticles can interact with oxygen during radiation and to avoid it, inert atmosphere radiation is performed by using nitrogen and argon gas. Examples of polymers crosslinked by radiation method involve polyvinyl alcohol, polyethylene glycol, and polyacrylic acid.

\section{d) Chemically Crosslinked Hydrogels}

Polymers having functional groups like $-\mathrm{OH},-\mathrm{COOH},-\mathrm{NH} 2$, is soluble in water and hydrogels are prepared by forming a covalent linkage between the polymer chains and complementary reactivity, such as amine-carboxylic acid due to the presence of functional groups. Hydrogels of polymers containing $-\mathrm{OH}$ groups like polyvinyl alcohol are prepared by using glutaraldehyde as a crosslinking agent. Due to the addition, reactive functional groups present on the polymer reacts with the crosslinking agent. Unreacted agents have to be extracted because these agents are highly toxic. Organic solvents are used to carry out the reaction and water can react with the crosslinking agent. After the formation of hydrogels, the drug is loaded on this and released as the first-order release.

\section{e) Physically Crosslinked Hydrogels}

The covalent crosslinking agent is known to be toxic. Reversible ionic crosslinking is utilize to overcome this problem and to form hydrogels. The formation of a network through ionic bridges between the polymeric chains occurs when chitosan reacts with a positively charged component like ions or molecules. It is a simple and mild procedure. Auxiliary molecules like catalysts are not required in contrast to covalent crosslinking. Polyelectrolyte complex with polyacrylic acid can be formed by chitosan polymer. (9)

\section{POLYMER USED IN IN-SITU GEL:}

1. The polymers and their degradation products should be nontoxic and non-absorbable from the gastrointestinal tract.

2. It should adhere quickly to the moist tissue and should possess some site-specificity.

3. It should not irritate the mucous membranes.

4. It should possess a wide safety margin both locally and systemically.

5.The value of the polymer should be not too high so that the prepared dosage form remains Competitive. (2) 


\section{DIFFERENT POLYMERS USED FOR THE PREPARATION OF IN-SITU GELLING SYSTEM:}

\section{A) Polymer used for $\mathrm{pH}$-sensitive In-situ gelling system}

a) Carbopol: Carbopol polymers are having excellent water sorption property. Carbopol polymer swell in water up to 1000 times by its original volume and 10 times their original diameter to form a gel when exposed to a $\mathrm{pH}$ environment above 4.0-6.0 because the pKa of those polymers is $6.0 \pm 0.5$. It is a high relative molecular weight, a cross-linked polyacrylic acid derivative and has a strong Mucoadhesive property. If there's an addition of cellulose then it'll reduce polymer concentration and improve a gelling property. Carbopol 934 and Carbopol 981 are mostly used as gelling agents. The Mucoadhesive property is due to electrostatic interaction or hydrophobic interaction, hydrogen bonding. It is an acidic molecule. When dispersed in water, the carboxylic group of the molecule partially dissociates and forms a coil. As it is a pH-sensitive polymer, an increase in the $\mathrm{pH}$ of the solution results in swelling of the polymer. The gelling effect is started with two stages, neutralization of solution by addition of, sodium hydroxide.(2)

\section{B) Polymer used for temperature-sensitive In-situ gelling system}

a) Poloxamer: Poloxamer is a water-soluble tri-block copolymer consisting of two polyethylene oxide and polypropylene oxide core in an ABA configuration. Poloxamer is also known as pluronic. Poloxamer has good thermal setting property and increased residence time of the drug. It acts as a gelling agent and solubilizing agent. Poloxamer gives colorless, transparent gel. Depending on the ratio and distribution of hydrophilic and hydrophobic chain different molecular weights are available and it has different gelling properties. It consists of central polypropylene oxide surrounded by polyethylene oxide. At temperature $\left(25^{\circ} \mathrm{C}\right)$, it acts like a viscous liquid and it gets transformed to form a transparent gel when temperature increases $\left(37^{\circ} \mathrm{C}\right)$. It forms a small micellar subunit in solution and increases in temperature results increase in viscosity result in swelling to make large micellar cross-linked network at a lower temperature.(2)

\section{b) Xyloglucan}

Xyloglucan is obtained from tamarind seeds and is composed of a (1-4)- $\beta$-D-glucan backbone chain, which has (1-6)- $\alpha$-D xylose branches that are partially substituted by (1-2)- $\beta$-D-galactoxylose. When its partially degraded by $\beta$ galactosidase, the obtained product exhibits thermally reversible gelation by the lateral stacking of the rod-like chains. The temperature of phase transition sol-gel transition varies with the degree of galactose elimination. It forms the thermally reversible gels on warming to body temperature. Xyloglucan has the main application in oral delivery exploits the proposed slow gelation time (several minutes) that might allow in-situ gelation within the stomach following the oral administration of chilled xyloglucan solution. Xyloglucan gels mainly used for oral, intraperitoneal, ocular and rectal drug delivery.(2)(12)

\section{c)Chitosan}

Chitosan is obtained by alkaline deacetylation of chitin, a natural component of shrimp and crab shell. Chitosan has a biodegradable, thermosensitive, polycationic polymer. Chitosan is a pH-dependent cationic polymer. Chitosan has biocompatible property, which remains dissolved in aqueous solutions up to a pH of 6.2. Neutralization of aqueous solution of chitosan to a $\mathrm{pH}$ exceeding up to 6.2 leads to the formation of a hydrated gel-like precipitate. The
$\mathrm{pH}$ gelling cationic polymer solution is transformed to the thermally sensitive pH-dependent gel-forming aqueous solutions, in absence by chemical changes by the addition of polyol salts bearing one anionic head like glycerol, sorbitol, fructose or glucose phosphate salts to chitosan aqueous solution.(11)(7)

\section{C)Polymer used for ion-sensitive In-situ gelling system-}

a) Sodium alginate: sodium alginate is a salt of alginic acid. It is extracted from brown algae. It has a linear block polysaccharide containing two type monomers $\beta$-DMannuronic acid and $\alpha$-L glucuronic acid residues connected by 1,4 glycosidic linkages. Sodium alginate biodegradable and non-toxic which exhibit good mucoadhesive property due to the presence of the carboxylic group. The mechanism of polymer is the monomers of alginate $\beta$-D-Mannuronic acid and $\alpha$-L glucuronic acid are arranged as M-M block with altering sequence (M-G) block. Upon interaction of G block of polymer with calcium, moieties give in the formation of a gel. On G: $M$ ratio the mechanical strength and porosity of hydrogel depends, type of crosslinker used and concentration of alginate polymer solution.(5)

\section{b)Gellangum}

Gellan gum polymer is an anionic deacetylated exocellular polysaccharide obtained by Pseudomonas elodea with a tetrasaccharide repeating unit of one $\alpha$-L rhamnose, one $\beta$ D-glucuronic acid, and two $\beta$-D-glucuronic acid residues. Gellan gum has the property of gelation which is both temperature-dependent or cations induced. This gelation process involves the formation of double-helical junction zones followed by aggregation of the double-helical segments to make a three-dimensional network by complexation with cations and hydrogen bonding with water. The formulation consisted of a gellan solution with calcium chloride and sodium citrate complex. When administered orally, the calcium ions are released in the acidic environment of the stomach leading to gelation of gellan thus forming a gel in situ. In situ gelling gellan formulation as a vehicle for oral delivery of theophylline is reported.(5)

\section{c) Pectin}

Pectins are a family of polysaccharides, in which the backbone of polymer mainly contains $\alpha$-(1-4)-D-galacturonic acid residues. Low methoxy pectins (degree of esterification $<50 \%$ ) readily form gels in aqueous solution in the presence of free calcium ions, which crosslink the galacturonic acid chains in a manner described by the egg-box model. Although the gelation of pectin will occur in the presence of $\mathrm{H}+$ ions, a source of divalent ions, generally calcium ions is required to produce the gels that are suitable as vehicles for drug delivery. The main advantage of using pectin for these formulations is that it is water-soluble, so organic solvents are not necessary for the formulation. Divalent cations present in the stomach, carry out the transition of pectin to gel state when it is administered orally. Calcium ions in the complex form may be included in the formulation for the induction of pectin gelation.(11)(7)

\section{d) Xanthum gum}

Xanthan gum is a high molecular weight extracellular polysaccharide produced by the fermentation of the gramnegative bacterium Xanthomonas campestris. The primary structure of this naturally produced cellulose derivative contains a cellulosic backbone ( $\beta$ - D-glucose residues) and a trisaccharide side chain of $\beta$-D-mannose- $\beta$-D-glucuronic acid- $\alpha-D$-mannose attached with alternate glucose residues of the main chain. The anionic character of this polymer is 
due to the presence of both glucuronic acid and pyruvic acid groups in the side chain.(11)

\section{EVALUATION PARAMETERS OF NASAL IN-SITU GELS}

1) Clarity: The clarity of in situ gel is find out by visual inspection under the black and white background.(2)

2) Sol-gel transition temperature and gelling time: For In-Situ gel-forming systems, the sol-gel transition temperature and $\mathrm{pH}$ should be determined. Gelling time is the time required for the first detection of gelation of the in-situ gelling system. Thermosensitive in-situ gel should be checked for in-situ gelling at body temperature.(2)(11)

3) Gelling capacity: Mix in-situ gel with simulated nasal fluid (in the proportion of 25:7 i.e. application volume $25 \mu \mathrm{l}$ and volume of nasal fluid in the nasal is $7 \mu \mathrm{l}$ ) to find out the gelling capacity of the ophthalmic product. The gelation may be assessed visually by noting the time for and time is taken for the dissolution of the formed gel. (2)

4) Viscosity: The viscosity and rheological properties of the polymeric formulations, either in solution or in a gel made with artificial tissue fluid and may be determined with different viscometers like Brookfield viscometer, cone, and plate viscometer. The viscosity of these formulations should be such that it should be patient compliance.(2)

5) Texture analysis: The firmness, consistency, and cohesiveness of formulation may be determined using a texture analyzer which mainly indicates the syringe ability of sol so the formulation can easily be administered in-vivo.(2)

6) In vitro drug release studies: For in-situ formulations to be administered by oral, ocular, or intranasally the drug release studies are carried out with the plastic dialysis cell. The cell is made up of the twocompartment, a donor compartment and a receptor compartment. Both cells are separated with the help of the cellulose membrane. The formulation is placed in the donor compartment. The specific volume of the receptor solution can be removed at specific time intervals and replaced with the fresh media. This receptor solution is analyzed for the drug release using an analytical method.(2)

7) Sterility testing: Sterility testing is carried out as per the IP 1996. Incubate the formulation for not less than 14 days at $300^{\circ}-350^{\circ} \mathrm{C}$ in the fluid thioglycolate medium to find the growth of bacteria and at $200^{\circ}-250^{\circ} \mathrm{C}$ in soyabean casein digest medium to find the growth of fungi in the formulation. (2)

8) Accelerated stability studies: Formulation is replaced in amber-colored vials and sealed with aluminum foil for the short term accelerated stability at $40^{\circ} \pm 20^{\circ} \mathrm{C}$ and $75 \pm 5 \% \mathrm{RH}$ as per ICH state guidelines. (2)

9) Appearance: Insitu nasal gel is examined visually for clarity in sol and gel form. (9)

10) $\mathbf{p H}$ of gel: With the help of a $\mathrm{pH}$ meter $\mathrm{pH}$ of in situ nasal gel is measured. (9)

11) Measurement of Gelation Time: $2 \mathrm{ml}$ of formulation gel is taken in a test tube and kept in an oven at $37^{\circ} \mathrm{C}$ temperature. At specific time gelation of in situ gel is examined.(11)

\section{2) Critical Ionic Concentration (CIC):}

Critical ionic concentration was an important parameter of ionic in situ gel, indicating the minimum ionic concentration that promoted phase transition. Simulated nasal fluid (SNF) was prepared: $8.77 \mathrm{~g} \mathrm{NaCl}, 2.98 \mathrm{~g} \mathrm{KCl}$, and $0.59 \mathrm{~g} \mathrm{CaCl} 2$ were dissolved in $1 \mathrm{~L}$ distilled water. In $1 \mathrm{~mL}$ of in situ gel solution, artificial nasal fluid was mixed in an ampoule, respectively. After $30 \mathrm{~s}$, the gels are adhered to the bottom of bottles without flowing, shows that the gels formed. The normal physiological temperature of the human nasal cavity is $32^{\circ} \mathrm{C}-34^{\circ} \mathrm{C}$. All measurements were taken at $34^{\circ} \mathrm{C}$ and made in triplicate.(13)

\section{3) Water Holding Capacity:}

$1 \mathrm{ml}$ of the formulation was accurately transferred and put in a centrifuged EP tube that had been accurately weighed.250 $\mu \mathrm{L}$ of artificial nasal fluid was then added and mixed, respectively. The gel quality was accurately weighed and recorded as $W_{0}$. This gel was centrifuged for $10 \mathrm{~min}$ at $8000 \mathrm{rpm}$, and the separate water layer was blotted by filter papers. The final gel quantity was weighed accurately and recorded as W. All measurements were taken at $34^{\circ} \mathrm{C}$ and tested in triplicate.(13)

$$
\text { Water holding capacity }=\frac{W}{W 0} \times 100 \% \text {. }
$$

\section{4) Volume Expansion Coefficient:}

$1 \mathrm{~mL}$ of In situ gel was removed accurately into a graduated test tube, in that $250 \mu \mathrm{L}$ of artificial simulated nasal fluid was added and mixed it, and volume was recorded as $1.25 \mathrm{~mL}$. 2 mLsimulated artificial nasal fluid was added and then in situ gel was formed after phase changes; the final volume was recorded as $\mathrm{V}_{\mathrm{T}}$. Therefore, the volume of the gel after phase transition was $V_{G}, V_{G}=V_{T}-2.0$. Each sample was tested three times at $34^{\circ} \mathrm{C}$. The expansion coefficient, $\mathrm{S} \%$, of the gel was described as:(13)

$$
\mathrm{S} \%=\frac{V G-V \mathrm{M}}{V M} \times 100 \%
$$

\section{5) Nasal Mucociliary Transport Time}

To compare the residence time of in situ gel in the nasal cavity the method is a physiological saline solution containing methylene blue dye at a concentration of 5 $\mathrm{mg} / \mathrm{mL}$ and formulation in situ gel with the same methylene blue content were prepared. By intramuscular injection of sodium thiopental $(7 \mathrm{mg} / \mathrm{mL})$ rats $(\mathrm{n}=5)$ were anesthetized. $10 \mu \mathrm{L}$ of each sample was infiltrated into the right nostril of the rat using a micropipette, respectively. By using wet cotton swabs the throats of the rats were wiped, and the appearance time of the blue dye was recorded. Each sample was examined in triplicate.(13)

\section{6) In Vitro Mucoadsorption Strength:}

It is the force required to separate the nasal mucosa and formulations. By using an improved physical balance method the in vitro bioadhesion was measured. Briefly, fresh goat nasal mucosa obtained from the local slaughterhouse was transported in PBS (phosphate-buffered saline, $\mathrm{pH}$ 7.4) and used within $5 \mathrm{~h}$. The nasal cavity was cut longitudinally along the nasal septum, and the nasal mucosa with a thickness of $0.6 \mathrm{~mm}$ was separated from the nasal olfactory area. The two mucosas were fixed to the openings of the two same glass vials by cyanoacrylate adhesive combined with thin wire; the mucosa side was outward, and the exposed area of the nasal cavity film was A $\left(\mathrm{cm}^{2}\right)$. An empty 
polyethylene bag was connected at one end of the balance scale, and the bottom of one of the glass bottles was connected at the other end, with the bottle mouth downward. The second glass bottle mouth was upward, as for the lifting platform, to balance gravity. On the mucous membrane of the glass bottle below $50 \mathrm{mg}$ gel was evenly distributed, and the height of the lifting platform was adjusted to make the mucous membrane come into contact with the gel of the two glass bottles, and the balance was in the equilibrium position. A certain force was applied to make both sides contact each other and the gel for $2 \mathrm{~min}$. On another site of balance dropwise water was added to the empty polyethylene tape. The weight of the water (m) was recorded when the mucosa was separated from the gel. The experiment was performed in triplicate. By the following formula the in vitro mucoadsorption strength was obtained:

$$
\text { Detachment Stress }=\frac{m \times g}{A}
$$

where $\mathrm{m}$ is the weight added to the balance in grams; $\mathrm{g}$ is the acceleration due to gravity (taken as $980 \mathrm{~cm} . \mathrm{s}^{-2}$ ); A is the surface area of the mucosal tissue in $\mathrm{cm}^{2}$.(13)

\section{7) TEM and SEM:}

A small quantity of formulation was placed on the carbon film after dilution and dried for $12 \mathrm{~h}$ naturally. By using scanning electron microscopy the morphology of a formulation was studied. The formulation was lyophilized and then sprayed with gold for the observation.(13)

\section{8) Drug content determination:}

The vials containing the formulation were shaken for 2-3 min manually and $100 \mu \mathrm{L}$ of the preparation was transferred to $25 \mathrm{ml}$ volumetric flasks with a micropipette and the final volume was made up with phosphate buffer $\mathrm{pH}$ 6.2. The amount of drug was determined using UV-vis spectrophotometer (UV 2600, Chemito, India).(8)

\section{9) Gel strength determination:}

Gel strength is expressed in terms of in seconds required by a $35 \mathrm{~g}$ piston for penetration of $5 \mathrm{~cm}$ distance, from the $50 \mathrm{~g}$ gel formulation. This test was performed using the 'Gel strength apparatus' modified at the laboratory. Gel (50g) was placed in a $100 \mathrm{ml}$ measuring cylinder. Gelation was induced by SNF. The apparatus for measuring gel strength (weight:35g) was then placed onto the gel. The gel strength was measured as the time (in seconds) required moving the apparatus $5 \mathrm{~cm}$ down through the gel. (8)

\section{0) Ex vivo permeation study:}

Fresh nasal tissues were obtained from the nasal cavity of sheep the local slaughterhouse. A piece of the nasal mucosa was mounted as a flat sheet in a two-chamber diffusion cell maintained at $37 \pm 0.5 \circ \mathrm{C}$ with the mucosal side facing the donor compartment. Phosphate buffer $\mathrm{pH} 7.4$ was placed in the receptor compartment. After a preincubation time of 20 min, $2 \mathrm{~mL}$ formulations were placed on the mucosal surface in the donor compartment. Gelation was induced by simulated nasal fluid. At a predetermined time interval, 0.5 $\mathrm{ml}$ samples were withdrawn from the receiver compartment and replacing the sampled volume with phosphate buffer $\mathrm{pH}$ 7.4 after each sampling, for a period of $10 \mathrm{~h}$. Samples so withdrawn were suitably diluted and analyzed spectrophotometrically (UV 2600, Chemito, India) at a specific wavelength. Permeability coefficient $(p)$ in $\mathrm{cm} / \mathrm{h}$ was calculated by the following formula:

$$
\mathrm{p}=\frac{\mathrm{dQ} / \mathrm{dt}}{\mathrm{C} 0 \mathrm{~A}}
$$

where dQ/dt is flux or permeability rate $(\mathrm{mg} / \mathrm{h}), \mathrm{C} 0$ is the initial concentration of drug in the donor compartment and $A$ is the effective surface area of the nasal mucosa. The cumulative of salbutamol sulphate permeated per unit area was plotted against time, and the slope of the linear portion of the plot was used as a steady-state flux, dQ/dt.(8)

\section{1) Histopathological studies:}

Histopathological studies were performed on isolated nasal mucosa obtained from the sheep. The nasal mucosa tissues were carefully removed from the nasal cavity of sheep obtained from the local slaughterhouse. Tissues were immediately used after separation. The evaluation of tissue incubated in phosphate buffer ( $\mathrm{pH}$ 6.2) was compared with tissue incubated in the diffusion chamber of Franz cell with in situ gel formulations. Tissue was fixed in $10 \%$ buffered formalin ( $\mathrm{pH}$ 6.2), routinely processed, and embedded in paraffin after these paraffin sections were cut and stained with hematoxylin and eosin. The sections were examined by optical microscopy (Motic, China), to examine the morphological changes to the tissue by a pathologist blinded to the study. (8)

\section{2) Fourier transform infrared spectroscopy and thermal analysis:}

During the gelation process, the nature of interacting forces can be evaluated using this technique by employing the potassium bromide pellet method. (11)

\section{3) Thermogravimetric analysis:}

Thermogravimetric analysis is used for the formulation of forming polymeric systems to quantitate the percentage of water in the hydrogel.(2)

\section{4) Differential Scanning Calorimetry:}

Differential scanning calorimetry is used to check if there are any changes in thermograms as compared with the pure ingredients and excipients used thus indicating the interactions. DSC thermograms of the formulation (stored at $40 \pm 2^{\circ} \mathrm{C} / 75 \% \pm 5 \% \mathrm{RH}$ for 2 months) were recorded. All the samples were placed into sealed aluminum pans and scanned at a heating rate of $10^{\circ} \mathrm{C}$ min- 1 over the temperature range of $30-200^{\circ} \mathrm{C} .(6)$ 
Table 4: In situ gelling systems

\begin{tabular}{|c|c|c|c|c|c|c|}
\hline Sr.no & Stimulus responsive agent & $\begin{array}{l}\text { Triggering } \\
\text { factor }\end{array}$ & Drug & Category & Year & Ref \\
\hline 1 & Gellan Gum & Ionic & Huperzine & Antialzimers & 2006 & $(14)$ \\
\hline & & & & & 2008 & (15) \\
\hline 2 & Gellan Gum & Ionic & $\begin{array}{l}\text { Metoclopramide } \\
\text { Hydrochloride }\end{array}$ & Antiemetic & 2010 & $(16)$ \\
\hline 3 & Chitosan & Thermal & Ropinirole & Antiparkinsons & 2010 & $(17)$ \\
\hline 4 & Carbopol 934 & $\mathrm{pH}$ & Zolmitriptan & Antimigraine & 2013 & $(18)$ \\
\hline 5 & $\begin{array}{l}\text { Poloxomer } 407, \\
\text { Poloxomer } 188\end{array}$ & Thermal & Rasagiline & Antiparkinsons & 2013 & \\
\hline 6 & Pluronic PF127 & Thermal & Curcumin & Antialzimers & 2013 & (19) \\
\hline 7 & Gellan Gum & Ionic & Sumatriptan & Antimigraine & 2013 & $(20)$ \\
\hline 8 & Pluronic PF127 & Thermal & Levodopa & Antiparkinsons & 2013 & $(21)$ \\
\hline 9 & Pluronic PF127 & Thermal & $\begin{array}{l}\text { Tramadol } \\
\text { Hydrochloride }\end{array}$ & Antidepressant & 2014 & $(22)$ \\
\hline 10 & Chitosan & Thermal & Doxepine & Antidepressant & 2014 & (23) \\
\hline 11 & PF-127 & Hydrochloride & $\begin{array}{l}\text { Phenylephrine } \\
\text { Hydrochloride }\end{array}$ & Antiallergic Rhinitis & 2016 & $(24)$ \\
\hline 12 & Gellan Gum & Ionic & Salbutamol Sulphate & Antiasthmatic & 2016 & $(8)$ \\
\hline 13 & Poloxomer 407 & Thermal & Timolol Maleate & Antihypertensive & 2016 & $(25)$ \\
\hline 14 & Pluronic PF127 & Thermal & Ropinirole & Antiparkinsons & 2016 & $(26)$ \\
\hline 15 & Pluronic PF127 & Thermal & Amantidine & Antiparkinsons & 2016 & (27) \\
\hline 16 & Poloxomer 188 & Thermal & $\begin{array}{l}\text { Fluticasone } \\
\text { Propionate }\end{array}$ & Antiallergic rhinitis & 2017 & (28) \\
\hline 17 & $\begin{array}{l}\text { Poloxomer 407, } \\
\text { Poloxomer } 188 \\
\end{array}$ & Thermal & Geniposide & Neurodegenerative & 2017 & (29) \\
\hline 18 & Gellan Gum & Ionic & Lorazepam & Antiepileptic & 2017 & $(30)$ \\
\hline 19 & Gellan Gum & Ionic & $\begin{array}{l}\text { Fluoxitine } \\
\text { Hydrochloride }\end{array}$ & Antidepressant & 2017 & (31) \\
\hline 20 & Pluronic PF127 & Thermal & Revastigmine & Antialzimers & 2017 & $(32)$ \\
\hline 21 & Pluronic PF127 & Thermal & Agomelatine & Antidepressant & 2017 & (33) \\
\hline 22 & Poloxomer 188 & Thermal & $\begin{array}{l}\text { Nortriptyline } \\
\text { Hydrochloride }\end{array}$ & Antidepressant & 2017 & (34) \\
\hline 23 & Pluronic PF127 & Thermal & $\begin{array}{l}\text { Revastigmine } \\
\text { Hydrogen Tartrate }\end{array}$ & Antialzimers & 2017 & (35) \\
\hline 24 & Carbopol 934 & $\mathrm{pH}$ & Paliperidone & Antischizophrenic & 2017 & $(36)$ \\
\hline 25 & Poloxomer 407 & Thermal & $\begin{array}{l}\text { Montelukast } \\
\text { Sodium }\end{array}$ & Antiasthmatic & 2018 & (37) \\
\hline 27 & Gellan Gum & Ionic & $\begin{array}{l}\text { Donepezil } \\
\text { Hydrochloride }\end{array}$ & Antialzimers & 2018 & (38) \\
\hline 28 & Gellan Gum & Ionic & Chromolyn Sodium & Antiasthmatic & 2019 & (39) \\
\hline 29 & Carbopol 934 & $\mathrm{pH}$ & Zolpidem & Insomnia & 2019 & $(40)$ \\
\hline 30 & Gellan Gum & Ionic & Paeonol & Antiparkinsons & 2019 & (13) \\
\hline 31 & Gellan Gum & Ionic & Resveratrol & Antialzimers & 2019 & (41) \\
\hline 32 & Gellan Gum & Ionic & Resveratrol & Antialzimers & 2016 & (42) \\
\hline
\end{tabular}

\section{CONCLUSION}

Nasal drug delivery is fast emerging field as an alternative route for the administration of drugs and biomolecules that are susceptible to enzymatic or acidic degradation, undergo first pass hepatic metabolism, are incompletely absorbed in the GIT or produce undesirably slow effects when administered orally. Nasal route circumvents bioavailability issues associated with listed factors and also offers the advantage of controlled drug delivery for extended periods of time. The success of a controlled release product is directly linked to patient compliance which in situ gels can offer. Exploitation of polymeric in situ nasal gels for controlled release of drug provides numerous advantages over conventional dosage forms and can be considered as reliable and non-invasive drug delivery system. Exploration of novel gel triggering mechanisms and use of water-soluble, biodegradable polymers for product development of the in situ nasal gel formulations makes them more acceptable.

\section{REFERENCES:}

1. N TN, R DM. An Overview on In-Situ Nasal Gel for Drug Delivery. 2019;11(7):695124.

2. Chand P, Gnanarajan G, Kothiyal P. In situ gel : A Review. Indian J Pharm Biol Res ( IJPBR). 2016;4(2):11-9.

3. Karavasili C, Fatouros DG. Smart materials: In situ gel-forming systems for nasal delivery. Drug Discov Today. 2016; 21(1):157-66.

4. Kaur P, Garg T, Rath G, Goyal AK. In situ nasal gel drug delivery: A novel approach for brain targeting through the mucosal membrane. Artif Cells, Nanomedicine Biotechnol. 2016; 44(4):1167-76.

5. J.U.Kute, A. B. Darekar RBS. in Situ Gel-Novel Approach for Nasal Delivery. World J Pharm Pharm Sci. 2014; 3(i):187-203.

6. Prasanth V V, Grace D, Parambi T, Vinod B, Mathew ST, Sheri PS. in-Situ Nasal Gels - an Update. 2016; 5(11):591-612.

7. Ban MM, Chakote VR, Dhembre GN, Rajguru JR, Joshi DA. inSitu Gel for Nasal Drug Delivery Original Research Article inSitu Gel for Nasal Drug Delivery. 2018; (March).

8. Salunke SR, Patil SB. Ion activated in situ gel of gellan gum containing salbutamol sulphate for nasal administration. Int J 
Biol Macromol [Internet]. 2016; 87(February):41-7. Available from: http://dx.doi.org/10.1016/j.ijbiomac.2016.02.044

9. Devi R, Chaudhary A, Pandit V. Mucoadhesive insitu nasal gelA novel approach. J Adv Drug Deliv. 2014; 1(6)

10. Vibha B. In Situ Gel Nasal Drug Delivery System - A Review. Indian J Pharma Sci. 2014; 4(3):577-80.

11. Nirmal HB, Bakliwal SR, Pawar SP, College PSGVPM. In-Situ gel : New trends in Controlled and Sustained Drug Delivery System. 2010; 2(2):1398-408.

12. Nirmal HB, Bakliwal SR, Pawar SP. In-Situ gel: New trends in controlled and sustained drug delivery system. Int J PharmTech Res. 2010; 2(2):1398-408.

13. Xie H, Li L, Sun Y, Wang Y, Gao S, Tian Y, et al. An available strategy for nasal brain transport of nanocomposite based on PAMAM dendrimers via in situ gel. Nanomaterials. 2019; 9(2).

14. Tao T, Zhao Y, Yue P, Dong WX, Chen QH. Preparation of huperzine A nasal in situ gel and evaluation of its brain targeting following intranasal administration. Yaoxue Xuebao. 2006; 41(11):1104-10.

15. Shinde J V, Mali KK, Dias RJ, Havaldar VD, Mahajan NS. Insitu Mucoadhesive Nasal Gels of Metoclopramide Hydrochloride : Preformulation and Formulation Studies. J Pharm Res. 2008; 1(1):88-96.

16. Mahajan HS, Gattani S. In situ gels of Metoclopramide Hydrochloride for intranasal 4delivery: In vitro evaluation and in vivo pharmacokinetic study in rabbits. Drug Deliv. 2010; 17(1):19-27.

17. Khan S, Patil K, Bobade N, Yeole P, Gaikwad R. Formulation of intranasal mucoadhesive temperature-mediated in situ gel containing ropinirole and evaluation of brain targeting efficiency in rats. J Drug Target. 2010; 18(3):223-34.

18. Mahakalkar NG, Upadhye KP. Research Article Zolmitriptan Nasal. 2013; 22(2):206-13.

19. Chen X, Zhi F, Jia X, Zhang X, Ambardekar R, Meng Z, et al. Enhanced brain targeting of curcumin by intranasal administration of a thermosensitive poloxamer hydrogel. J Pharm Pharmacol. 2013; 65(6):807-16.

20. Galgatte UC, Kumbhar AB, Chaudhari PD. Development of in situ gel for nasal delivery: Design, optimization, in vitro and in vivo evaluation. Drug Deliv. 2014; 21(1):62-73.

21. Sharma S, Lohan S, Murthy RSR. Formulation and characterization of intranasal mucoadhesive nanoparticulates and thermo-reversible gel of levodopa for brain delivery. Drug Dev Ind Pharm. 2014; 40(7):869-78.

22. Kaur P, Garg T, Vaidya B, Prakash A, Rath G, Goyal AK. Brain delivery of intranasal in situ gel of nanoparticulated polymeric carriers containing antidepressant drug: Behavioral and biochemical assessment. J Drug Target [Internet]. 2015; 23(3):275-86. Available from: http://dx.doi.org/10.3109/1061186X.2014.994097

23. Naik A, Nair H. Formulation and evaluation of thermosensitive biogels for nose to brain delivery of doxepin. Biomed Res Int. 2014;2014.

24. Verma P, Prashar N, Chaudhary H. Nasal (In-situ) gel (Phenylepherine $\mathrm{HCl}$ ) for allergic rhinitis congestion treatment: development and characterization. Am J PharmTech Res. 2016; (July).

25. Jagdale S, Shewale N, Kuchekar BS. Optimization of Thermoreversible in Situ Nasal Gel of Timolol Maleate. Scientifica (Cairo). 2016;2016.

26. Rao M, Agrawal DK, Shirsath C. Thermoreversible mucoadhesive in situ nasal gel for treatment of Parkinson's disease. Drug Dev Ind Pharm. 2017; 43(1):142-50.

27. Lungare S, Bowen J, Badhan R. Development and Evaluation of a Novel Intranasal Spray for the Delivery of Amantadine. J Pharm Sci [Internet]. 2016; 105(3):1209-20. Available from: http://dx.doi.org/10.1016/j.xphs.2015.12.016
28. Khandagale PM, Rokade MM, Phadtare DG. Formulation Development and Evaluation of Nasal In-Situ Gel of Hydrocortisone. Asian J Pharm Technol. 2018; 8(2):92.

29. Wang $Y$, Jiang S, Wang H, Bie H. A mucoadhesive, thermoreversible in situ nasal gel of geniposide for neurodegenerative diseases. PLoS One. 2017; 12(12):1-17.

30. Shah V, Sharma M, Pandya R, Parikh RK, Bharatiya B, Shukla A, et al. Quality by Design approach for an in situ gelling microemulsion of Lorazepam via intranasal route. Mater Sci Eng C [Internet]. 2017; 75:1231-41. Available from: http://dx.doi.org/10.1016/j.msec.2017.03.002

31. Pathan IB, Mene H, Bairagi S. Quality by design (QbD) approach to formulate in situ gelling system for nose to brain delivery of Fluoxetine hydrochloride: Ex-vivo and In-vivo study. Ars Pharm. 2017; 58(3):107-14.

32. Abouhussein DMN, Khattab A, Bayoumi NA, Mahmoud AF, Sakr TM. Brain targeted rivastigmine mucoadhesive thermosensitive In situ gel: Optimization, in vitro evaluation, radiolabeling, in vivo pharmacokinetics and biodistribution. J Drug Deliv Sci Technol [Internet]. 2018; 43:129-40. Available from: https://doi.org/10.1016/j.jddst.2017.09.021

33. Fatouh AM, Elshafeey AH, Abdelbary A. Agomelatine-based in situ gels for brain targeting via the nasal route: Statistical optimization, in vitro, and in vivo evaluation. Drug Deliv [Internet]. 2017; 24(1):1077-85. Available from: https://doi.org/10.1080/10717544.2017.1357148

34. Pathan IB, More B. Formulation and characterization of intra nasal delivery of nortriptyline hydrochloride thermoreversible gelling system in treatment of depression. Acta Pharm Sci. 2017; 55(2):35-44.

35. Salatin S, Barar J, Barzegar-Jalali M, Adibkia K, Jelvehgari M. Thermosensitive in situ nanocomposite of rivastigmine hydrogen tartrate as an intranasal delivery system: Development, characterization, ex vivo permeation and cellular studies. Colloids Surfaces B Biointerfaces [Internet]. 2017; 159:629-38. Available from: http://dx.doi.org/10.1016/j.colsurfb.2017.08.031

36. Sherje AP, Londhe V. Development and Evaluation of $\mathrm{pH}$ Responsive Cyclodextrin-Based in situ Gel of Paliperidone for Intranasal Delivery. AAPS PharmSciTech. 2018; 19(1):384-94.

37. Durgapal S, Rana M, Mukhopadhyay S, Rana AJ, Goswami L Joshi S. Formulation and Evaluation of in-Situ Nasal Gel of Montelukast Sodium for the Effective Treatment of Asthma. Int J Pharm Sci Res. 2018; 9(7):2792-9.

38. Patil RP, Pawara DD, Gudewar CS, Tekade AR. Nanostructured cubosomes in an in situ nasal gel system: an alternative approach for the controlled delivery of donepezil $\mathrm{HCl}$ to brain. J Liposome Res [Internet]. 2019; 29(3):264-73. Available from: http://dx.doi.org/10.1080/08982104.2018.1552703

39. V SCM, P AK, Manjunath K, Kulkarni S V. Development Characterization and Evaluation of Nasal in situ Gel containing Anti-Asthmatic Drug. 2019; 7(3):3001-6.

40. Karpagavalli L, Gopalasrsatheeskumar K, Narayanan N, Maheswaran A, Raj AI, Priya JH. Formulation and Evaluation of Zolpidem Nasal in Situ Gel. World J Pharm Res. 2017; 6(2)

41. Rajput AP, Butani SB. Resveratrol anchored nanostructured lipid carrier loaded in situ gel via nasal route: Formulation, optimization and in vivo characterization. J Drug Deliv Sci Technol [Internet]. 2019; 51(February):214-23. Available from: https://doi.org/10.1016/j.jddst.2019.01.040

42. Hao J, Zhao J, Zhang S, Tong T, Zhuang Q, Jin K, et al. Colloids and Surfaces B : Biointerfaces Fabrication of an ionic-sensitive in situ gel loaded with resveratrol nanosuspensions intended for direct nose-to-brain delivery. Colloids Surfaces B Biointerfaces [Internet]. 2016; 147:376-86. Available from: http://dx.doi.org/10.1016/j.colsurfb.2016.08.011 